\title{
The Second Canadian Gastroesophageal Reflux Disease Consensus: Moving forward to new concepts
}

\author{
ABR Thomson MD PHD FRCPC FACP FACG ${ }^{1}$, N Chiba MD FRCPC ${ }^{2}$, D Armstrong MD FRCP ${ }^{3}$, G Tougas MC CM FRCPC ${ }^{3}$, \\ RH Hunt FRCP FRCPED FRCPC FACG ${ }^{3}$
}

ABR Thomson, N Chiba, D Armstrong, G Tougas, RH Hunt. The Second Canadian Gastroesophageal Reflux Disease Consensus: Moving forward to new concepts. Can J Gastroenterol $1998 ; 12(8): 551-556$

Gastroesophageal reflux disease (GERD) is a disease with serious consequences that may result in significant impairment in quality of life and disease morbidity. Across all grades of severity of symptoms and severity of underlying esophageal disease, proton pump inhibitors (PPIs) provide therapeutic gains over prokinetics (PKs) or $\mathrm{H}_{2}$ receptor antagonists $\left(\mathrm{H}_{2} \mathrm{RAs}\right)$. The potential cost effectiveness of using medications with higher acquisition costs that may lower health care costs overall is often disregarded when conducting cost comparisons with medications having lower 'up-front' costs. Limiting therapy to less effective agents condemns many patients to protracted suffering, repeated physician visits and needless reinvestigation of symptoms that could have been resolved by appropriate initial therapy. Based on current data, use of any classification of symptom severity as a basis for selecting one class of therapeutic agents over another for first line therapy (ie PKs, $\mathrm{H}_{2} \mathrm{RA}$ s for 'mild' GERD, versus a PPI for 'severe' disease) is unwarranted.

Key Words: Gastroesophageal reflux disease, $\mathrm{H}_{2}$ receptor antagonists, Prokinetics, Proton pump inhibitors, Step-down therapy, Step-up therapy

\section{Deuxième consensus canadien sur le reflux gastro-œsophagien : de nouveaux concepts en vue}

RÉSUMÉ : Le reflux gastro-œsophagien est une maladie qui a des conséquences graves et qui peut entraîner une atteinte de la qualité de vie et une morbidité significatives. Peu importe l'intensité des symptômes et le degré d'atteinte œsophagienne, les inhibiteurs de la pompe à protons (IPP) offrent des avantages thérapeutiques supérieurs à ceux des procinétiques ou des anti- $\mathrm{H}$. Le rapport coût-efficacité potentiel des médicaments plus coûteux qui peuvent faire baisser les dépenses globales en soins de santé est souvent négligé lorsque l'on procède à des comparaisons de coûts sur des médicaments avec pour objectif de toujours obtenir le prix direct le plus bas. En limitant le traitement à des agents moins efficaces, on condamne de nombreux patients à une souffrance inévitable, à des visites répétées chez le médecin et à des examens superflus pour des symptômes qui auraient pu être soulagés dès le départ avec un traitement adéquat. Sur la base des données actuelles, l'emploi d'une classification des symptômes selon leur gravité pour choisir une classe d'agents thérapeutiques par rapport à une autre en traitement de première intention (p. ex., procinétique, anti-H pour le RGO bénin vs IPP pour une maladie grave) n'est pas justifié.

\footnotetext{
${ }^{1}$ Division of Gastroenterology, Department of Medicine, University of Alberta, Edmonton, Alberta; ${ }^{2}$ Surrey GI Clinic, Guelph and McMaster University, Hamilton, Ontario; and ${ }^{3}$ Division of Gastroenterology, McMaster University, Hamilton, Ontario

Correspondence and reprints: Dr ABR Thomson, Division of Gastroenterology, Department of Medicine, University of Alberta, Edmonton,

Alberta T6G 2C2. Telephone 403-492-6490, fax 403-492-7964, e-mail alan.thomson@ualberta.ca

Received for publication July 9, 1998. Accepted July 14, 1998
} 
$\mathrm{T}$ he publication of the Second Canadian Gastroesophageal Reflux Disease Consensus Conference on the management of patients with gastroesophageal reflux disease (GERD) (1) was awaited with considerable interest and expectation. Publication of the document took place 15 months after the conference in June 1996, reflecting the time needed to write and revise the manuscript to incorporate revisions requested by the 38 participants who attended the conference. The many controversies involved, particularly regarding the step-up versus the step-down approach to therapy, lengthened the publication process. Moreover, because of the lack of previously approved rules of revision, revisions in the cognitive aspects of the document were necessary in order to incorporate more recently available literature. Consensus signifies agreement, and the nature of the controversy surrounding the development of a treatment algorithm, and the immense commercial implications involved, implied the need to reduce the protocol to the lowest common denominator of physician comfort rather than aspiring to the heights of idealism for the best approach based on evidence and common sense.

This paper examines new evidence, reassesses old data and interprets possible choices for treatment of patients with GERD, all of which form the basis for the proposal that stepdown therapy is the only treatment for patients with GERD that can be supported by the evidence. Step-down therapy denotes a short two- to four-week course of therapy with a proton pump inhibitor (PPI), after which the patient is reassessed. At the time of reassessment the physician may initiate a step-down to a lower dose or intermittent PPI therapy, 'less potent' $\mathrm{H}_{2}$ receptor antagonist $\left(\mathrm{H}_{2} \mathrm{RA}\right)$ therapy or prokinetic $(\mathrm{PK})$ therapy. Endoscopy is not necessary to diagnose GERD and is indicated only if the patient has alarm symptoms, or if reflux symptoms persist or recur despite adequate therapy. Patients who require long term maintenance therapy should undergo an elective, 'once-in-a-lifetime' endoscopy to screen for Barrett's esophagus, provided that they are eligible for, and desirous of, appropriate therapy if Barrett's esophagus is diagnosed.

\section{LIMITED USE OF A SYMPTOM SEVERITY SCALE}

Table 4 in the introductory article of the consensus document outlines an arbitrary clinical scale estimating the symptom severity of GERD (1). Although it is a plausible scale,

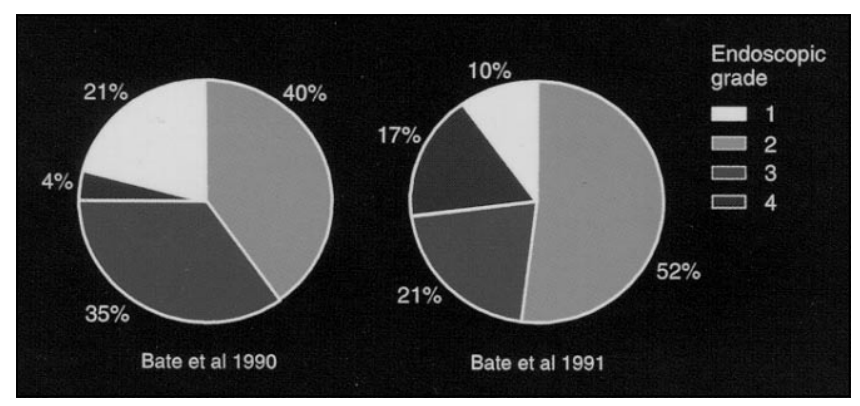

Figure 1) Esophagitis by endoscopic grade in patients with mild symptoms of acid reflux disease. Data from references 3,4 no data exist to substantiate the classification of symptoms as 'mild' if they have been present for less than six months, if they occur less than three times per week or if the patient rates symptom intensity as 'three or less' on an undefined scale of 10. It is well documented that the symptoms of acid reflux disease are not reliable predictors of the presence or severity of underlying esophagitis. Mild symptoms may mask the presence of severe esophagitis (2-5). For example, approximately $80 \%$ of patients classified as having mild symptoms of acid reflux disease had underlying esophagitis grades two to four, and nearly $40 \%$ had esophagitis grades three and four (Figure 1). Furthermore, a recent meta-analysis of pooled data from 16 independent clinical trials that studied a total of 3478 patients with acid reflux disease demonstrated that approximately $70 \%$ of patients experienced moderate to severe heartburn, irrespective of the severity of the underlying esophagitis (6). Thus, patients with mild symptoms may have severe erosive esophagitis, and patients who do not have erosive esophagitis may experience severe symptoms. Furthermore, 'mild' symptoms, or a diagnosis of 'mild' esophagitis, are not a guarantee of a good response to 'mild' or less potent therapy. Even for patients with grade II erosive esophagitis, the group that comprises approximately $62 \%$ of patients studied in clinical trials (7), there is a major therapeutic gain using PPIs over $\mathrm{H}_{2} \mathrm{RAs}$; the rate of healing and symptom relief is approximately twice as fast (7).

The symptom severity scale was introduced partly because it was recognized that primary care physicians base patient management largely on symptoms. However, to be useful in practice a symptom scale should first be validated to ensure that it can provide a predictable basis for determining appropriate investigation and treatment strategies. Because the symptom scale proposed by the consensus guidelines has not been validated, a number of practical management problems are created:

- Very mild symptoms may require little, if any, therapy, but there are no data to indicate an appropriate threshold for initiating therapy.

- The presence of 'mild' symptoms may mask severe mucosal damage that will not respond to treatment with lifestyle modifications or $\mathrm{H}_{2}$ RAs.

- There are no data to indicate that PPI therapy is medically inappropriate for some patients with 'mild' symptoms.

- The duration of symptoms for more than six months has no bearing on symptom severity; it is simply indicative of chronicity.

- Limiting the initial use of PPIs deprives physicians of a potentially cost effective diagnostic tool. In the patient who has typical symptoms, a good symptomatic response to a short course of PPI therapy is virtually diagnostic of reflux disease. Provided that the patient's response to therapy is assessed within two weeks, a step-down approach need not be more costly. 


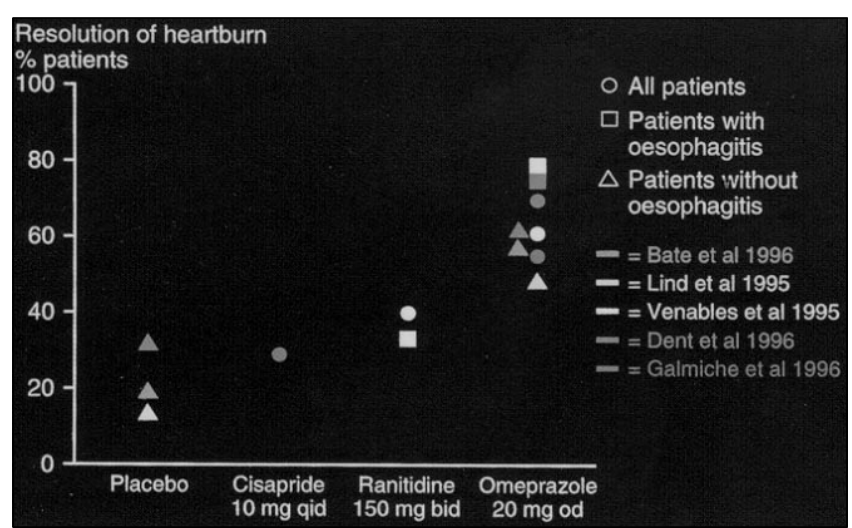

Figure 2) Resolution of heartburn in patients with symptomatic acid reflux disease. Data from references 12-16

In conclusion, current data do not warrant use of any classification of symptom severity as a basis for selecting one class of therapeutic agents over another for first line therapy (ie, PK or $\mathrm{H}_{2} \mathrm{RA}$ for 'mild' GERD, versus PPI for 'severe disease').

\section{MILD THERAPY IS LIMITED FOR MILD SYMPTOMS OR MILD ESOPHAGITIS}

Some physicians are uncomfortable prescribing 'potent' PPI therapy to relieve symptoms arising from a condition that they consider to be relatively trivial; however, GERD is not a trivial condition. Using either the Psychological General Well-Being (PGWB) index or the Gastrointestinal Symptomatic Rating Scale (GSRS), it is clear that reflux symptoms, with or without associated esophagitis, significantly impair quality of life (8-11). Accepting that there is a dissociation between the severity of symptoms and the severity of underlying esophageal disease, employing a step-up approach to therapy withholds effective PPI therapy from patients who require effective acid inhibition. Furthermore, PPIs are superior to PKs and $\mathrm{H}_{2}$ RAs for treating mild symptoms arising in patients with endoscopy-negative reflux disease (ENRD) and across all grades of erosive esophagitis. In five large, double-blind trials including over 2500 patients with GERD, with or without associated esophagitis, omeprazole provided better symptom relief than ranitidine $150 \mathrm{mg}$ bid or cisapride $10 \mathrm{mg}$ qid (12-16). The therapeutic gains at four weeks with omeprazole $20 \mathrm{mg}$ administered once daily were $21 \%$ over ranitidine $(\mathrm{P}<0.0001)$ and $26 \%$ over cisapride $(\mathrm{P}<0.01)$; omeprazole $10 \mathrm{mg}$ daily produced therapeutic gains of $9 \%$ and $13 \%$, respectively (Figure 2 ). Differences were also noted between PPI and PK (16). Omeprazole also produced therapeutic gains of $28 \%$ to $30 \%$ over placebo in the four-week resolution of heartburn $(12,13,15)$. Rapid symptom relief was achieved in primary care patients who had heartburn, with or without esophagitis (16). Regurgitation was also decreased, and quality of life (PGWB scale) was normalized $(9,11)$. PPIs consistently produced higher healing rates than $\mathrm{H}_{2} \mathrm{RAs}$ in patients with erosive esophagitis, irrespective of the severity of the esophagitis (2), and without the development of tolerance that occurs with $\mathrm{H}_{2} \mathrm{RA}(17-20)$.

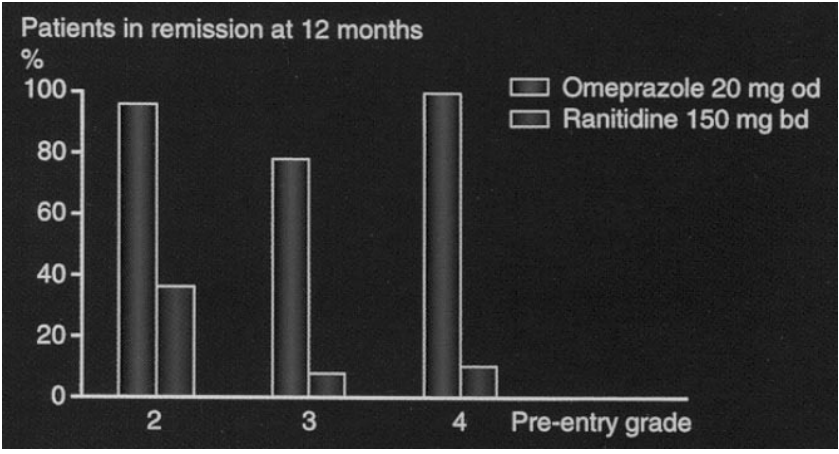

Figure 3) Predictable maintenance treatment with omeprazole in reflux esophagitis, irrespective of pre-entry grade

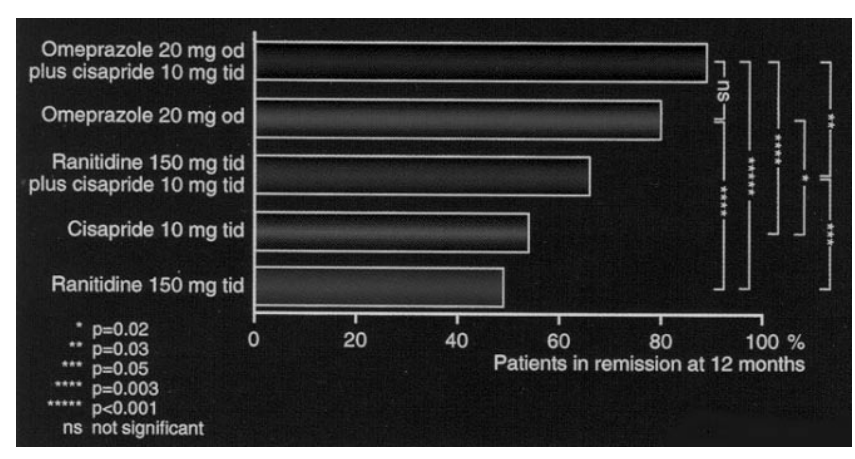

Figure 4) Omeprazole is superior to ranitidine and cisapride in maintaining pateints with healed reflux esopagitis in long term endoscopic remission

It is noteworthy that much of the controversy about choice of therapy is related to the 'up-front' (acquisition) cost of therapy. PPIs are used less often not because they are too 'potent', but because they are relatively costly. If PPIs and $\mathrm{H}_{2} \mathrm{RAs}$ were equal in price, little, if any, controversy regarding step-up versus step-down therapy would exist; however, most cost comparisons consider only 'up-front' drug acquisition costs. The Canadian Coordinating Office for Health Technology Assessment health economic analysis indicates that using more costly medications may reduce overall health care costs provided that they are more effective. Thus, because of the rapid and high rate of symptom resolution achieved with PPIs and the higher probability of complete healing of associated esophagitis, the patient with GERD can be managed more effectively, whether the endpoint is resolution of symptoms, improved quality of life or healing of esophagitis. Limiting therapy to less effective agents condemns many patients to protracted suffering, repeated physician visits and needless reinvestigation of symptoms that could have been relieved by appropriate initial therapy.

\section{LIMITED USE OF PKS AND $\mathrm{H}_{2} \mathrm{RAs}$ FOR MAINTENANCE THERAPY}

The healing of erosive esophagitis and resolution of reflux symptoms are a temporary respite for nearly two-thirds of patients with GERD. Despite effective acute therapy, symp- 


\section{Typical GERD Symptoms as Primary Complaint (No Alarm Features)}

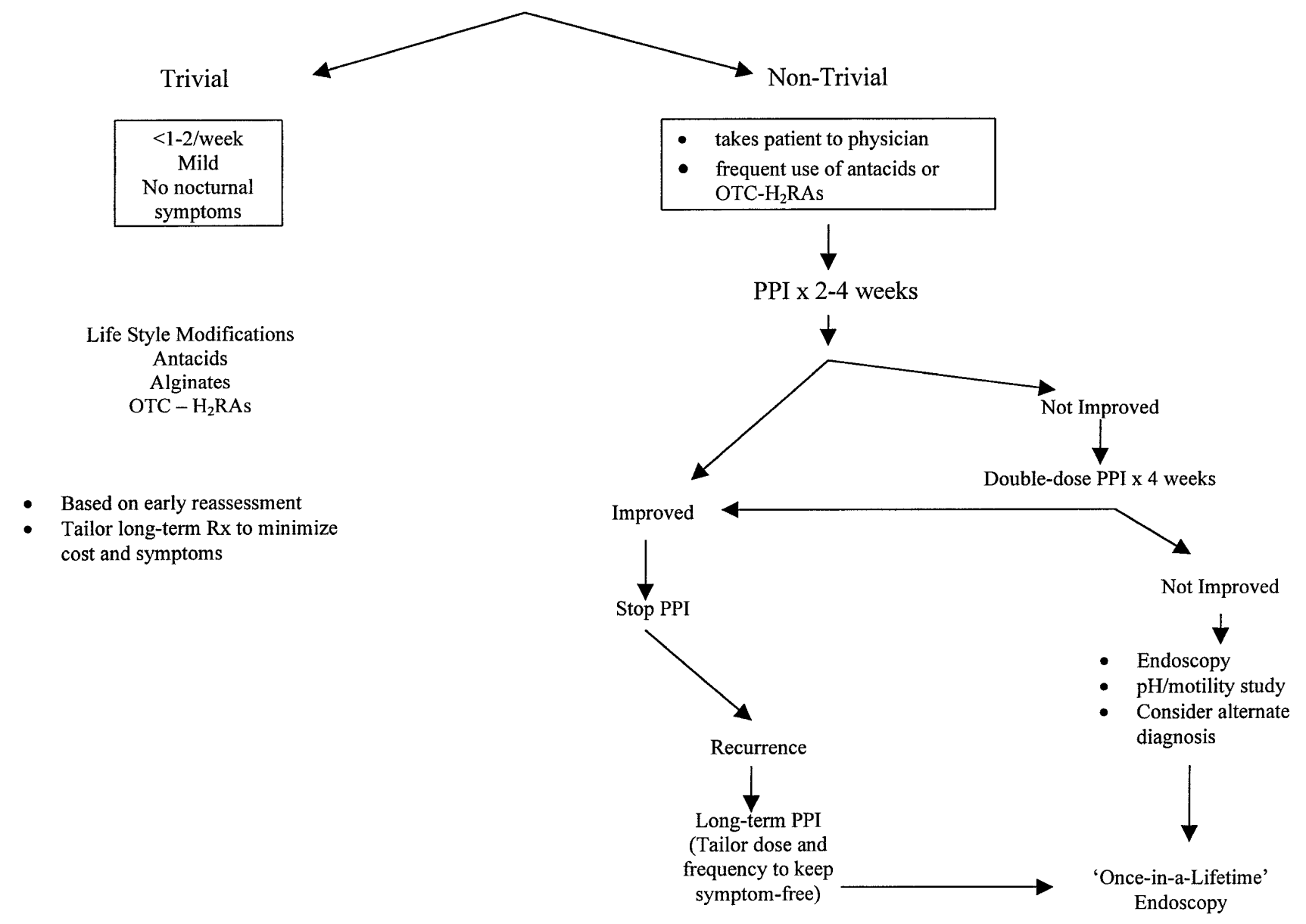

Figure 5) Suggested approach to patients with typical gastroesophageal reflux disease (GERD) symptoms. OTC- $\mathrm{H}_{2} \mathrm{RA}$ Over-the-counter histamine $\mathrm{H}_{2}$ receptor antagonists; $\mathrm{pH}$ Ambulatory esophageal $\mathrm{pH}$ monitoring; PPI Proton pumb inhibitor; $\mathrm{Rx}$ Reaction

toms and esophageal erosion recur in the majority of patients with reflux esophagitis and, in studies of patients with erosive esophagitis, relapse rates of $80 \%$ to $90 \%$ have been documented within six to 12 months of stopping therapy (21). Thus, maintenance therapy is indicated for a substantial proportion of patients who initially require acute medical therapy. The Second GERD Consensus Conference, therefore, recommended that these patients be maintained on the agent that had been successfully used to treat their reflux symptoms and/or erosive esophagitis. However, regardless of which therapeutic agent was used initially and of the severity of the reflux esophagitis, PPIs produce higher symptomatic and endoscopic remission rates than do $\mathrm{H}_{2} \mathrm{RAs}$ or PKs (Figures 3,4). Although $\mathrm{H}_{2} \mathrm{RAs}$ are effective for some patients with mild GERD, they are of questionable efficacy in patients with more severe erosive esophagitis (SavaryMiller grades two to four) (21).
For patients with erosive esophagitis, PPIs clearly provide a superior outcome in terms of symptom relief and freedom from recurrent esophageal injury. However, particularly in the primary care setting, it is impractical to arrange for endoscopy in all patients with reflux symptoms, either at initial presentation or after therapy. Thus, in most instances physicians must rely on symptoms to gauge disease severity and treatment success. The relevance of studies conducted in patients with erosive esophagitis in primary care practice remains controversial, but recent studies suggest that $29 \%$ to $51 \%$ of reflux patients have erosive esophagitis $(14,22-24)$. Patients with endoscopy-positive reflux disease are indistinguishable, with respect to symptom severity, from patients with ENRD (6). These observations, combined with studies showing that PPIs provide better symptom relief than PKS or $\mathrm{H}_{2} \mathrm{RAs}$ in patients with ENRD $(14,16)$, strongly suggest that PPIs are superior for maintenance therapy over the full 
spectrum of GERD. It is also irrelevant whether some GERD patients develop recurrent symptoms in the absence of erosive esophagitis. Symptomatic ENRD is a chronic condition $(10,25)$; about half of these patients experience recurrent symptoms within six months of stopping prescription therapy, despite the use of antacids. Using short courses of PPIs to treat symptomatic recurrences is sensible, given their superior pain relief compared with $\mathrm{PKs}$ or $\mathrm{H}_{2} \mathrm{RAs}$ $(7,14,16)$.

Is there any risk that intermittent use of PPIs for recurrent symptoms increases the risk of the patient developing a complication? Follow-up of patients who initially had mild esophagitis showed that more severe esophagitis later occurred in $20 \%$ of these patients (26). There is no evidence that intermittent PPI therapy reduces this risk, but there is also no evidence that it increases the risk of progression. Furthermore, because PPIs provide a greater likelihood of healing recurrent esophagitis, independent of an overall increase in the propensity for severe esophagitis, it is more likely that the risk of esophageal ulceration or stricture will be decreased (27).

\section{FOR CONSIDERATION}

Optimal therapy for patients with GERD eliminates reflux symptoms and prevents the development of complications. The symptom pattern correctly predicts the diagnosis of GERD in at least two out of three patients (28), and self administered questionnaires may also facilitate the diagnosis of GERD (6,31). Many patients with GERD experience symptoms that are sufficiently severe to impair their quality of life $(29,30)$. The endoscopic severity of esophagitis correlates poorly with GERD symptom severity (31). In the absence of alarm symptoms, upper gastrointestinal series or endoscopy are not indicated (32). It is controversial whether endoscopy is indicated for patients with nonresponsive reflux symptoms, and $24 \mathrm{~h}$ esophageal $\mathrm{pH}$ monitoring may be required in patients with reflux symptoms that persist after administration of standard doses of a PPI to determine whether higher or more frequent doses are needed. If neither erosive disease nor Barrett's esophagus is found on initial endoscopy, further endoscopies are not indicated, even in the presence of continued symptoms.

Treatment with a PPI may be used effectively as a diagnostic therapeutic trial in patients with troublesome, but not alarm, symptoms of GERD (33-35). Health-related quality of life in patients with GERD is more likely to be restored by initial treatment with a PPI than with an $\mathrm{H}_{2} \mathrm{RA}$ $(9,10,15,36,37)$. The debate continues as to whether step-up therapy is the preferred strategy or whether PPIs should be considered the only appropriate therapy for symptoms of GERD. Antacids, alginates, over-the-counter $\mathrm{H}_{2} \mathrm{RAs}$ and lifestyle changes are appropriate therapy for trivial or infrequent heartburn or regurgitation. However, most patients have self-medicated by the time they consult a physician. Recommending step-up therapy is not warranted when the consequences of ineffective or less effective treatment include persistent symptoms, impaired quality of life, time lost from work and repeated physician visits. Thus, the step-up approach is difficult to support because it delays the institution of adequate therapy. Inadequate therapy ultimately leads to more health care dollars being spent on repeated physician visits, specialist consultations and investigations, only to culminate in prescribing a PPI that could have initiated therapy in a step-down approach.

Thus, step-up therapy is impractical and inadequate for many patients. Step-down therapy is only limited in that some patients may be adequately managed with less potent, or initially less costly, therapy; however, three-quarters of patients treated by the step-up approach suffer the consequences of suboptimal therapy. The cost of PPIs is greater than that of generic $\mathrm{H}_{2}$ RAs. The economic argument, which is based on drug acquisition costs, is often used to support the step-up approach: use cheaper therapy in all patients with the hope that endoscopy, complications, poor quality of life and the later need for a PPI can be avoided. However, less potent therapy is not necessarily less costly. Acquisition costs for PKs are almost comparable with those for PPIs, and, there is, therefore, little support for endorsing the recommendation of the Second GERD Consensus Conference that PKs be considered as first-line therapy. PK therapy should be considered not because it is less potent, but because there are accompanying indicators of altered gastrointestinal motility that may respond appropriately to this class of medication.

The cost of caring for patients with GERD goes far beyond the cost of the initial physician consultation and the initial prescription cost. Failure of therapy may lead to follow-up visits, referral and investigations, all of which are costly. Most patients, if they were properly and honestly informed, would not tolerate enduring unpleasant, suboptimal symptom relief because funding agencies only support the use of less effective therapies based on lower initial, up-front drug acquisition costs. Properly designed clinical trials with prospective evaluation of the downstream health care costs are urgently required to settle these important issues.

More debate about better strategies of management, more studies and more patient-oriented discussions are required. A simple approach to the patient with GERD symptoms is proposed to initiate the process of further discussion (Figure 5). Let's hear from you - what is your viewpoint?

ACKNOWLEDGEMENTS: We thank Dr WG Paterson of Queen's University for suggestions and comments and Ms RS Jacobs for skilled word processing assistance.

\section{REFERENCES}

1. Beck IT, Champion MC, Lemire S, Thomson ABR, eds. Second Canadian Gastroesophageal Reflux Disease Consensus Conference. Can J Gastroenterol 1997;11(Suppl B):1B-112B.

2. Bate CM, Keeling PWN, O'Morain C, et al. Comparison of omeprazole and cimetidine in reflux oesophagitis: symptomatic, endoscopic and histological evaluations. Gut 1990;31:968-72.

3. Bate CM, Crowe JP, Dickinson RJ, et al. Reflux oesophagitis resolves more rapidly with omeprazole, $20 \mathrm{mg}$ once daily, than with ranitidine, 
$150 \mathrm{mg}$ twice daily; omeprazole, $40 \mathrm{mg}$ once daily, provides further benefit in unresponsive patients. Br J Clin Res 1991;2:133-48.

4. Green JRB. Is there such an entity as mild oesophagitis? Eur J Clin Res 1993;4:28-34.

5. Galmiche J-P, Bruley des Varannes S. Symptoms and disease severity in gastro-oesophageal reflux disease. Scand J Gastroenterol 1994;29(Suppl 201):62-8.

6. Carlsson R, Frison L, Lundell L, et al. Relationship between symptoms, endoscopic findings and treatment outcome in reflux oesophagitis. Gastroenterology 1996;110(Suppl):A77.

7. Chiba N, de Gara CJ, Wilkinson JM, Hunt RH. Speed of healing and symptom relief in grade II to IV gastroesophageal reflux disease: a meta-analysis. Gastroenterology 1997;112:1798-810.

8. Dimenas E. Methodological aspects of evaluation of quality of life in upper gastrointestinal diseases. Scand J Gastroenterol 1993;28(Suppl 199):18-21.

9. Lind T, Havelund T, Glise H, et al. Omeprazole (OME) improves quality of life (QoL) in patients with endoscopy negative reflux disease (ENRD). Gastroenterology 1995;108(Suppl):A15.

10. Lind T, Havelund T, Pedersen SA, et al. On-demand treatment with omeprazole (OME) maintains quality of life (QoL) during long-term follow-up of patients with endoscopy negative reflux disease (ENRD). Gastroenterology 1996;110:A178.

11. Dent J, Watts R, Riley S, et al. Omeprazole improves quality of life $(\mathrm{QoL})$ in patients with gastroesophageal reflux disease (GERD). Gastroenterology 1996;110(Suppl):A94.

12. Lind T, Havelund T, Carisson R, et al. The effect of omeprazole (OME) $20 \mathrm{mg}$ and $10 \mathrm{mg}$ daily on heartburn in patients with endoscopy negative reflux disease (ENRD). Gastroenterology 1995;108(Suppl):A151.

13. Bate CM, Griffin SM, Keeling PWN, et al. Reflux symptom relief with omeprazole in patients without unequivocal oesophagitis. Aliment Pharmacol Ther 1996;10:547-55.

14. Venables T, Newland R, Patel AC, et al. A comparison of omeprazole $10 \mathrm{mg}$ and $20 \mathrm{mg}$ om with ranitidine $150 \mathrm{mg}$ bd for the treatment of GERD in primary care. Gut 1995;37(Suppl 2):A45. (Abst).

15. Dent J, Watts R, Riley S, et al. Gastroesophageal reflux disease (GERD) in primary care - an international placebo controlled study of different treatment strategies with omeprazole. Gastroenterology 1996;110(Suppl):A93.

16. Galmiche JP, Barthelemy P, Barret S, et al. Comparison of omeprazole $20 \mathrm{mg}$ and $10 \mathrm{mg}$ versus cisapride $10 \mathrm{mg}$ qid on the relief of heartburn: results of a randomised double-blind study. Gastroenterology 1996;110(Suppl):A113.

17. Nwokolo CU, Gavey CJ, Smith JTL, et al. Tolerance during 29 days of conventional dosing with cimetidine, nizatidine, famotidine or ranitidine. Gut 1989;30:A1487.

18. Rogers MJ, Primrose JN, Holmfield J, et al. 'Tolerance' to $\mathrm{H}_{2}$-receptor antagonists: does it occur and by what mechanism? Gut 1989;30:A1489.

19. Decktor DL, Robinson M, Rodriguez SL, et al. $\mathrm{H}_{2}$-receptor antagonist tolerance and gastroesophageal reflux disease: an assessment of intraesophageal and intragastric $\mathrm{pH}$ during 28 days of standard therapy. Gastroenterology 1993;104:A64.

20. Hurlimann S, Abbuhl B, Inauen W, et al. Comparison of acid inhibition by either oral high-dose ranitidine or omeprazole. Aliment Pharmacol Ther 1994;8:193-201.

21. Chiba N. Proton pump inhibitors in acute healing and maintenance of erosive or worse esophagitis: A systematic overview. Can J Gastroenterol 1997;11(Suppl B):66B-73B.

22. Robinson M, Earnest D, Maton PN, et al. Frequent heartburn symptoms should not be ignored in subjects who self-treat with antacids. Gastroenterology 1996;110:A241. (Abst)

23. Galmiche JP, Barthelemy P, Hamelin B. Treating the symptoms of gastroesophageal reflux disease: a double-blind comparison of omeprazole and cisapride. Aliment Pharmacol Ther 1997;11:765-73.

24. Carlsson R, Brun J, Dent J, et al. Factors predicting response to omeprazole in patients with a clinical diagnosis of gastroesophageal reflux disease. Scand J Gastroenterol 1997;32(Suppl 224):F111. (Abst)

25. Venables T, Newland R, Patel A, Hole J, Turbitt M, Richardson P. Omeprazole $10 \mathrm{mg}$ once daily: effective maintenance for GERD in general practice. OESO 5th World Congress. Paris, September 3 to 7, 1996.

26. DeVault KR, Castell DO. Guidelines for the diagnosis and treatment of gastroesophageal reflux disease. Arch Intern Med 1995;155:2165-73.

27. Smith PM, Kerr GD, Cockel R, et al. A comparison of omeprazole and ranitidine in the prevention of recurrence of benign esophageal stricture. Gastroenterology 1994;107:1312-8.

28. Klauser AG, Schindlbeck NE, Muller-Lissner SA. Symptoms in gastro-oesophageal reflux disease. Lancet 1990;335:205-8.

29. Glise H. Quality of life and cost of therapy in reflux disease. Scand J Gastroenterol 1995;30(Suppl 210):38-42.

30. Glise H, Hallerback B, Johansson B. Quality-of-life assessments in the evaluation of gastroesophageal reflux and peptic ulcer disease before, during and after treatment. Scand J Gastroenterol 1995;30(Suppl 208):133-5.

31. Johnsson F, Joelsson B, Gudmundsson K, Greiff L. Symptoms and endoscopic findings in the diagnosis of gastroesophageal reflux. Scand J Gastroenterol 1987;22:714-8.

32. Axon ATR, Bell GD, Jones RH, Quine MA, McCloy RF. Guidelines on appropriate indications for upper gastrointestinal endoscopy. BMJ 1995;310:853-6.

33. Schindlbeck NE, Heinrich C, Konig A, Dehndorfer A, Pace F, Muller-Lissner SA. Optimal thresholds, sensitivity, and specificity of long term $\mathrm{pH}$-metry for the detection of gastroesophageal reflux disease. Gastroenterology 1987;93:85-90.

34. Schindlbeck NE, Klauser AG, Berghammer G, Londong W, Muller-Lissner SA. Three year follow up of patients with gastro-oesophageal reflux disease. Gut 1992;33:1016-9.

35. Schindlbeck NE, Klauser AG, Voderholzer WA, Muller-Lissner SA. Mean acidity or percentage reflux time in oesophageal pH-monitoring. Eur J Gastroenterol Hepatol 1993;5:155-9.

36. Bardhan KD, Muller-Lissner S, Bigard MA, et al. The impact on quality of life in intermittent treatment (IT) with omeprazole (OM) and ranitidine (RAN) as strategies for the management of patients with symptomatic gastroesophageal reflux disease (GERD). Gastroenterology 1997;112 (Suppl 4):A65. (Abst)

37. Geraedts AAM, de Groot GH, Hazenberg BP, Amsterdam OLVG, and The Dutch Reflux Study Group. Omeprazole therapy improves quality of life in patients with reflux oesophagitis. Gastroenterology 1994;106(Suppl 4):A80. (Abst) 


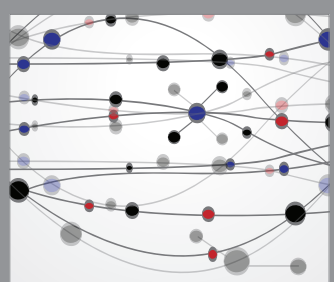

The Scientific World Journal
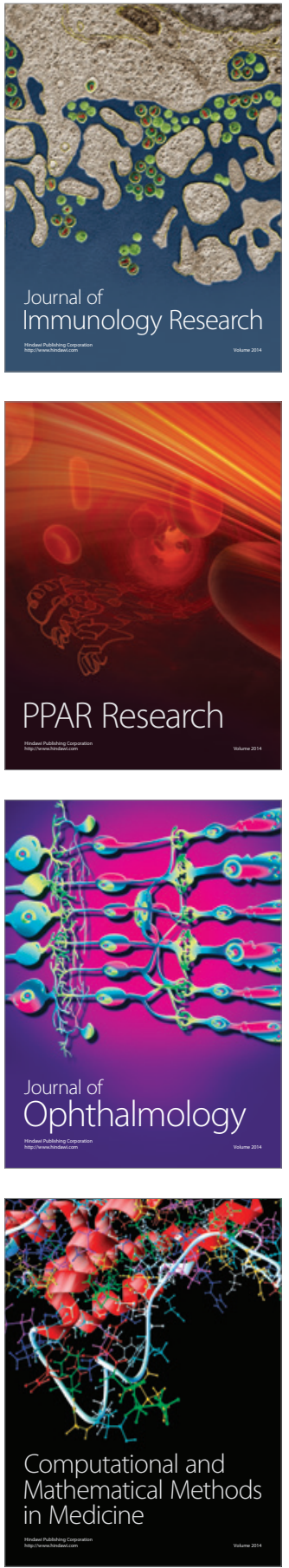

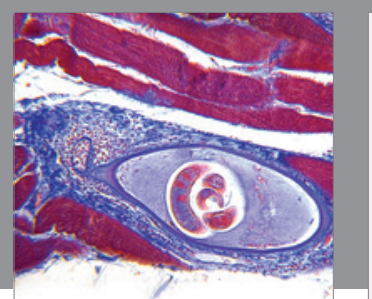

Gastroenterology Research and Practice

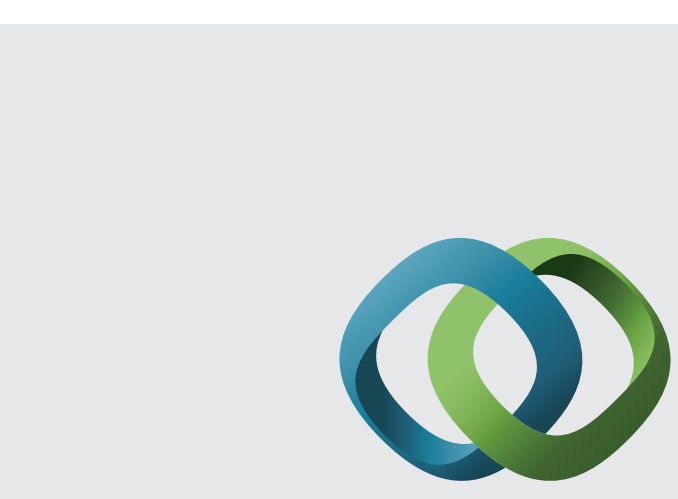

\section{Hindawi}

Submit your manuscripts at

http://www.hindawi.com
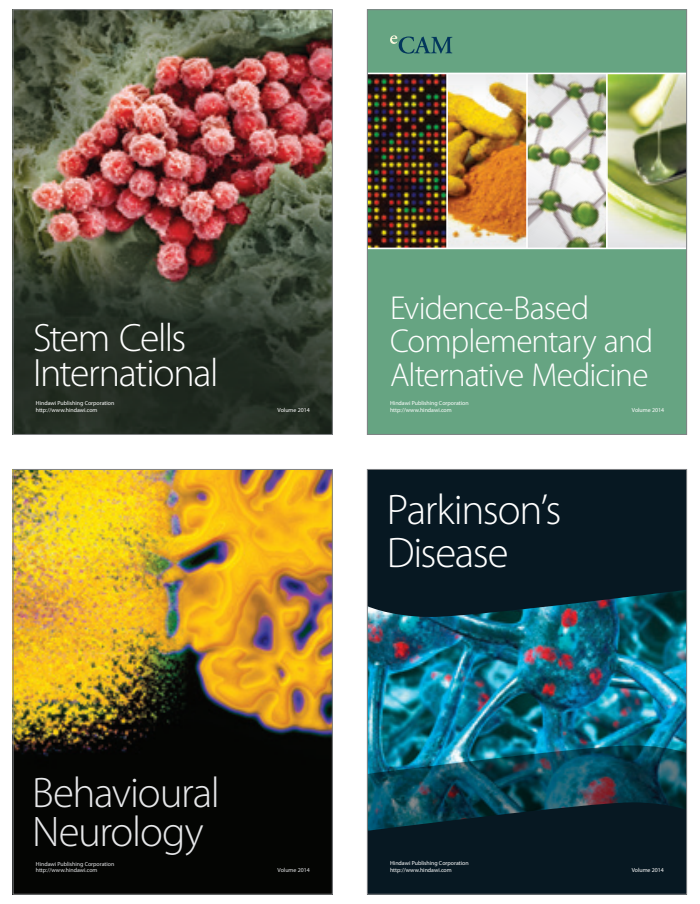
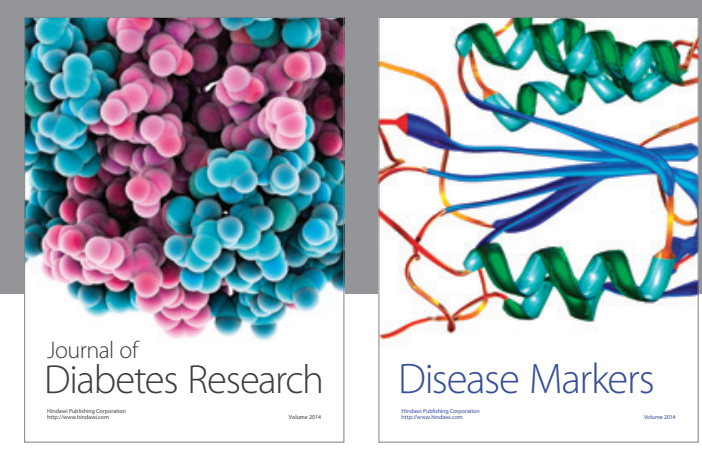

Disease Markers
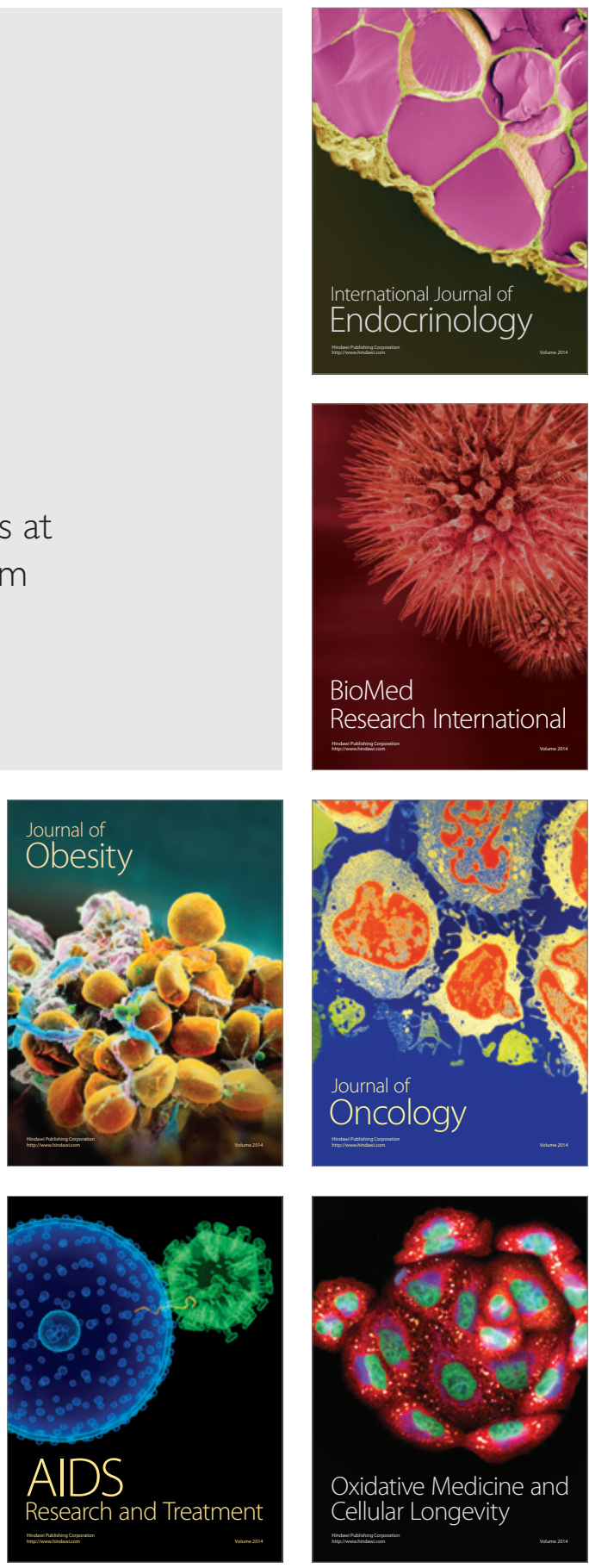